\title{
AÇÕES COLETIVAS PARA A PROMOÇÃO DE EXPORTAÇÕES DO SETOR APÍCOLA BRASILEIRO: O CASO DA ASSOCIAÇÃO ABEMEL
}

\section{COLLECTIVE ACTIONS TO PROMOTE THE BRAZILIAN BEEKEEPING INDUSTRY EXPORT: THE CASE OF THE ABEMEL ASSOCIATION}

Luiza Mariana Silveira Miranda

UnB - Universidade de Brasília luixamariana@yahoo.com.br

Submissão: $27 / 08 / 2014$

Aprovação: 29/10/2015 


\section{RESUMO}

Este trabalho discute, segundo a ótica de membros da Associação Brasileira dos Exportadores de Mel (ABEMEL), as contribuições das ações coletivas para a solução de barreiras à promoção das exportações do setor apícola brasileiro. No marco teórico, apontam-se as redes, as ações coletivas, a internacionalização, as exportações e suas principais barreiras. Trata-se de um estudo de caso de abordagem predominantemente qualitativa. A unidade de análise é a ABEMEL, composta por 32 membros, com sede em Rio Claro, São Paulo. Destaca-se como entidade representativa do setor apícola brasileiro. Para a coleta das evidências empíricas utilizaram-se questionário fechado e roteiro de entrevista aplicados via e-mail, com a participação de 10 respondentes do questionário e quatro entrevistados, além de entrevista com representante da gerência da ABEMEL e de análise documental. Procedeu-se à análise de conteúdo com categorização a priori e em pequena etapa quantitativa extraíram-se médias e desvio-padrão. Concluiu-se que os associados percebem ganhos advindos de ações coletivas mediadas pela associação, que atua como um dos atores relevantes para estruturação do setor apícola. Entretanto, são percebidos desafios ainda maiores que envolvem esforços contundentes por parte de atores governamentais e empresariais.

Palavras-chave: Ações coletivas. Promoção de exportações. Setor Apícola Brasileiro. 


\begin{abstract}
This work discusses, according to the Associação Brasileira dos Exportadores de Mel (ABEMEL) members point of view, the collective actions contribution in overcoming the obstacles to promote the Brazilian beekeeping industry export. The theoretical context goes through networks, collective actions, internationalization, exportation and its main barriers. This is a, mainly qualitative, case study. The unit of analysis is ABEMEL, constituted of 32 members, with headquarters in Rio Claro, São Paulo. It figures as a representative body of the Brazilian beekeeping industry. The empirical data was collected through a closed questionnaire and interviews, done by e-mail, 10 associates answered the questionnaire and 4 the interview, a representative of the executive management of ABEMEL was also interviewed and documents analyzed. The data was analyzed through content analysis with a priori categorization and a small quantitative stage by extracting means and standard deviations. It was concluded that the associates notice benefits brought by the collective actions mediated by the association, which acts as an important figure in structuring the beekeeping industry. However, even bigger challenges that require more forceful efforts by the government and the companies are also seen.
\end{abstract}

Keywords: Collective actions. promoting export. Brazilian beekeeping industry. 


\section{INTRODUÇÃO}

Redes sãoarranjos com propósitos claros, feitos entre empresas distintas, com vistas à obtenção de vantagens competitivas (JARILLO,1988) por meio de "cooperação e colaboração" (HALL, 2001). Assim, reúnem-se atributos complementares em estrutura única e representante, sustentada por ações uniformizadas, porém descentralizadas (BALESTRIN; VERSCHOORE, 2008). A cooperação pode ser uma alternativa organizacional para empresas que busquem competitividade sustentável em resposta à complexidade ambiental (DOTTO; WITMANN, 2003). Alguns possíveis ganhos advindos de redes de cooperação podem ser categorizados em: 1) ganhos de escala e poder de mercado; 2) acesso a soluções; 3) aprendizagem e inovação; 4) redução dos custos e dos riscos; e 5) relações sociais (VESHCOORE, 2006; BALESTRIN; VERSCHOORE, 2008).

Ao interessar-se pela internacionalização, sendo uma de suas formas a exportação, as pequenas empresas poderão vislumbrar nas ações coletivas um facilitador do acesso ao mercado externo. A internacionalização propicia à empresa a comercialização no exterior de produtos que exploram vantagens comparativas. Buckley et al., (2008), ao discutirem as tendências de expansão dos investimentos diretos na China, destacaram os deslocamentos conjuntos de projetos ou firmas como modo de entrada. Elencaram fatores motivadores, tais como as vantagens de localização, os ganhos percebidos, o envolvimento direto e indireto do governo nas decisões de internacionalização das pequenas empresas na década de 1990, entre outros aspectos. Existem motivações proativas para a internacionalização, que são os estímulos para alcançar uma meta definida; e motivações reativas, que influenciam as empresas a reagirem às mudanças do ambiente, em um processo de adaptação (PALACIOS; SOUSA, 2004).

Segundo a Conferência das Nações Unidas para Comércio e Desenvolvimento (UNCTAD) as Pequenas e Médias Empresas (PMEs) que investem no exterior enfrentam obstáculos, sendo os mais comuns: a falta de experiência internacional e de competência de gestão; a escassez de informação sobre oportunidades e ambientes de investimento; o acesso limitado ao financiamento; as diferenças e choques culturais; e a dificuldade de encontrar parceiros (UNCTAD, 2004).

A internacionalização da empresa "consiste em sua participação ativa nos mercados externos", sendo a exportação uma de suas formas (BRASIL/MRE, 2011, p.12). Exportar pressupõe boa postura profissional, conhecimento de normas, versatilidade, boa noção da capacidade exportadora e pesquisas e avaliações bem feitas, que melhorem a qualidade das decisões. Exporta-se para superar dificuldades no mercado interno; minimizar riscos, 
diversificar mercados, aperfeiçoar recursos humanos, desenvolver tecnologias e melhorar a qualidade do produto. Ressalte-se que capacidade exportadora não é apenas a avaliação da capacidade produtiva, mas também, a aptidão para adequar-se às variáveis e exigências do mercado internacional (MINERVINI, 2012).

Existem organizações e entidades públicas ou privadas que estruturam e facilitam o ingresso de exportadores ao mercado externo. Normalmente são criadas para alcançar objetivos estratégicos governamentais relacionados com o desenvolvimento das exportações. Entidades de fomento e organismos de governo (p. ex.: Câmara de Comércio Exterior (Camex), Ministério do Desenvolvimento, Indústria e Comércio Exterior (MDIC)/Secretaria de Comércio Exterior; Ministério das Relações Exteriores/ Departamento de promoção comercial (DPR); Agência de Promoção de Exportações do Brasil (Apex Brasil); Centros internacionais de Negócios (CIN); Iniciativas do Banco do Brasil, assim com do Programa de Apoio Tecnológico à exportação) podem estimular as exportações, por meio da promoção comercial, desoneração tributária, capacitação, melhores condições de financiamento, simplificação da logística, orientações para adaptação, estímulo aos investimentos em pesquisa e em ativo físico (LOPEZ, 2007; MDIC, 2009). Incluem-se nesse rol as redes como entidades autônomas que atuam como canais de acesso à informação, recursos, mercados e tecnologias. As redes podem, também, influenciar profundamente a conduta e o desempenho das empresas (GULATI et al., 2000).

A abordagem de redes foi inserida naturalmente nesta discussão, pois as interações via network podem facilitar a internacionalização, uma vez que a acesso a mercados estrangeiros pode ser viabilizado por relacionamentos negociais ou pessoais já existentes entre atores do mercado (HILAL; HEMAIS, 2003). Assim, amplia-se a visão da internacionalização para a potencialidade dos relacionamentos além-fronteiras (HILAL; HEMAIS, 2003). Propõe-se aqui que a atuação coletiva de pequenos produtores e exportadores contribui para o enfrentamento de obstáculos às exportações, tais como as barreiras: 1- por parte do exportador (p.ex.: defasagem tecnológica, idioma, preço, adequação do produto etc.); 2- por parte do país exportador (p.ex.: câmbio, trâmites alfandegários, custos portuários, burocracias e legislação etc.); 3- por parte do importador (p.ex.: prazos, condições de negociação etc.); 4- por parte do país importador (p.ex.: tributos, normas/padrões, cultura, vistos etc.) (MINERVINI, 2012). Entre os problemas enfrentados pela cadeia produtiva de mel estão: a insuficiência de investimentos em pesquisas, em particular para a exploração de mel orgânico e da criação de produtos com identidades locais e regionais; a inadequação do sistema de financiamento; o pouco domínio de tecnologias de produção, gestão e comercialização; as taxas de juros 
elevadas; a legislação inadequada. Talvez isso explique parcialmente o fato de o mel brasileiro ser visto como commodity, como a soja e o milho. (BUAINAIN; BATALHA, 2007).

Pressupõe-se, nesta discussão, que quando as empresas querem expandir-se para novos mercados, mas não dispõem de instrumentos, habilidades e conhecimentos necessários, podem buscar nas ações coletivas, o que precisam para encarar desafios e alcançar vantagem competitiva que possa ser explorada dentro e fora do país.

Segundo a Associação Brasileira dos Exportadores de Mel (ABEMEL), o Brasil é um dos polos produtores mundiais de alimentos, com crescimento significativo em produtividade e qualidade da agricultura (Planejamento Estratégico Setorial- PES, 2010), e possui os maiores reservatórios de fauna e flora mundial devido à sua biodiversidade internacionalmente reconhecida, que impõe ao país a preocupação com o desenvolvimento biotecnológico. $\mathrm{O}$ aumento dos esforços coletivos estimula e estrutura a organização tanto gerencial como produtiva do setor apícola (BUAINAIN; BATALHA, 2007). A construção de relacionamentos interorganizacionais tem sido estimulada porque são arranjos que podem colaborar com a promoção da "cultura da apicultura" no país, incentivando as inovações tecnológicas que, por sua vez, elevam a produtividade e a qualidade do mel e derivados.

Embora o mercado mundial do mel seja dominado pela Argentina, China e Alemanha como exportadores, e pelos Estados Unidos, Alemanha e Reino Unido, como importadores, não está fechado à entrada de novos produtores. Atualmente, o mel brasileiro é demandado devido à sua qualidade, que segue padrões mundiais de exigência fitossanitária. Em 10 anos, a produção triplicou e as exportações se elevaram mais de $9.000 \%$, segundo a Confederação Brasileira de Apicultura (BUAINAIN; BATALHA, 2007; RANGEL, 2011). Segundo dados da ABEMEL (2015), o Brasil é o $8^{\circ}$ maior exportador de mel do mundo, exportando em 2014 US\$ 98 milhões em mel.

$\mathrm{O}$ ato de organizar-se surge, muitas vezes, da incapacidade de resolver problemas solitariamente. Reunir esforços dos que têm as mesmas deficiências ou vivem situações semelhantes, é uma alternativa para enfrentá-las. Porém, a simples associação de produtores muitas vezes coloca produtos no mercado externo. Os maiores desafios do setor apícola são a falta de produção contínua; desconhecimento de alternativas de venda; sazonalidade da demanda; altas taxas de impostos e, às vezes, qualidade insatisfatória do produto que não atende ao mercado consumidor (PAULA NETO; ALMEIDA NETO, 2005). Desse modo, entender a percepção das empresas que atuam coletivamente pode ser um passo para o entendimento de gargalos, bem como uma fonte de informações que subsidiem decisões do 
setor, pois a inserção no mercado internacional, por meio da promoção comercial e das exportações, pode impulsionar o crescimento do setor (STAL, 2010).

Este estudo concentrou-se na pergunta: Como associados à Associação Brasileira dos Exportadores de Mel (ABEMEL) percebem as contribuições da ação coletiva como solução às barreiras à promoção das exportações do setor apícola brasileiro? Assim, o objetivo geral visou: discutir, na ótica de associados, as contribuições das ações coletivas para a solução de barreiras à promoção das exportações do setor apícola brasileiro. Os objetivos específicos buscaram: a) caracterizar o setor apícola no contexto das exportações Brasileiras; b) identificar as estratégias de ação coletiva desenvolvidas pela associação visando à promoção das exportações; c) identificar as motivações dos associados para integrar a ABEMEL; d) apresentar os ganhos das ações coletivas na ótica dos associados; e) identificar motivações dos associados para a exportação; f) identificar barreiras do setor para a exportação na ótica dos associados; g) identificar estratégias desenvolvidas pelos associados para superar as barreiras à exportação; h) identificar desafios futuros das ações coletivas.

A justificativa para realizar este estudo se refere à atualização de informações sobre este setor, pois, como relatado no documento "Cadeias Produtivas de Flores e Mel”, elaborado em 2007 em cooperação técnica entre o Instituto Interamericano de Cooperação para a Agricultura no Brasil (IICA), o Ministério da Agricultura, Pecuária e Abastecimento (MAPA) e a Agência Brasileira de Cooperação do Ministério das Relações Exteriores (ABC/MRE), por meio do Projeto de Cooperação Técnica BRA/IICA/04/005, há escassez bibliográfica e estatística de informações sobre produtos orgânicos e mel. Acerca do mel, as informações disponíveis variam e, não raramente, são conflitantes (BUAINAIN; BATALHA, 2007).

\section{MÉTODO}

O estudo de caso foi realizado com abordagem predominantemente qualitativa. A ABEMEL foi escolhida por estar vinculada a projetos setoriais da Apex promovendo ações coletivas e pela facilidade de acesso, além da representatividade junto a exportadores do setor apícola. Fundada em agosto de 2003, trata-se de pessoa jurídica de direito privado sem fins lucrativos e tem sede em Rio Claro, São Paulo. É órgão representativo, congregando pessoas jurídicas ligadas à exportação de mel do Brasil, com a finalidade de coordenar, representar e orientar as entidades que congrega, e atua como membro ativo na Câmara Setorial da Cadeia Produtiva do Mel.

O "mel de abelha" é oriundo das Unidades de Extração dos Produtos das Abelhas (UEPA), chamadas de "casas de mel” (destinadas à extração do mel das melgueiras que vêm do campo, 
decantação, acondicionamento, rotulagem, estocagem, envase do mel em baldes ou tambores e comercialização do produto a granel). Já o Entreposto dos Produtos das Abelhas (EPA) é o estabelecimento destinado ao recebimento, extração, seleção, classificação, beneficiamento, manipulação, industrialização, conservação, estoque, embalagem, acondicionamento, fracionamento, rotulagem, expedição e comercialização de produtos das abelhas e/ou fabricação de derivados (MAPA, 2011).

Dos 32 entrepostos associados à ABEMEL, 23 (72\%) participam de ações coletivas. Nas reuniões que ocorrem, em média, uma vez por mês, as empresas são representadas por proprietários/gestores. Há nove estados brasileiros representados pelos associados (aqui listados por suas siglas de UF: AL, CE, ES, PR, RS, PI, SC, MG, SP) e também o DF. Os estados que se destacam nas exportações são os estados: SP, RS, SC, PR, CE, PI e MG. Os estados listados, não são necessariamente os que mais produzem, mas os que têm melhores condições para exportar. Os principais mercados são: Estados Unidos, Alemanha, Japão, mercado árabe (kouche), França, Reino Unido e China.

Foram entrevistados sujeitos que participavam ativamente das ações coletivas e com representatividade nas exportações, sendo critérios para a escolha: participação nas reuniões da ABEMEL e nas ações coletivas, facilidade de acesso por internet e $e$-mail e predisposição para participar da pesquisa. A maioria dos sujeitos era composta por presidentes das empresas, com idade entre 40 e 50 anos, alta escolaridade, que participam de negociações que exigem poder de negociação e conhecimento de outras línguas e culturas. Não lidam diretamente com a produção do mel, mas com o seu processamento e comercialização.

As evidências empíricas foram coletadas por meio de documentos da associação, questionário respondido por 10 (dez) pessoas e roteiro de entrevistas presenciais, feitas com quatro associados e com a gerência executiva da ABEMEL, utilizando-se assim, triangulação de fontes e de dados. O questionário levantou informações sobre: Benefícios do Relacionamento em Rede, construído a partir de Veschoore (2006), com escala de concordância de 1 a 5. O roteiro de entrevista referiu-se ao processo de exportação, à participação e benefícios do relacionamento e das ações tomadas coletivamente, ao surgimento das ações coletivas via associação; o processo decisório na ABEMEL; ao acesso dos membros às ações coletivas; aos benefícios, vantagens, oportunidades que a associação oferece, e quais ações foram realizadas. Utilizou-se categorização a priori (BARDIN, 1977) para a análise das evidências empíricas, baseando-se no referencial teórico (VESCHOORE, 2006; BALESTRIN; VERSCHOORE, 2008) para estabelecer as categorias. Quanto ao questionário, reconheceu-se que a amostra obtida de 10 respondentes era reduzida para aplicar análise estatística robusta, do tipo 
inferencial. Por isso, foi feita apenas uma discussão descritiva dos cinco ganhos que compuseram as maiores médias em termos de nível de concordância dos associados com as assertivas apresentadas.

\section{RESULTADOS E DISCUSSÃO}

Os resultados são apresentados na ordem dos objetivos específicos e, para melhor compreensão, os respondentes do questionário foram codificados como participantes $(\mathrm{P}) \mathrm{de}$ P1 a P10 e os associados entrevistados (E) pela abreviação de E1, E2, E3, E4.

\subsection{O SETOR APÍCOLA NO CONTEXTO DAS EXPORTAÇÕES BRASILEIRAS.}

A cadeia produtiva do mel é simples e pouco organizada em termos de mecanismos formais de controle e negociação com o mercado. Nos últimos anos surgiu a tentativa de criar cadeias estruturadas em associações e cooperativas de apicultores, assim como de traders, com o fito de assegurar qualidade ao produto destinado ao exterior. A partir da produção, cultivo e extração, a cadeia produtiva do mel, toma duas direções: o processamento e beneficiamento próprio, ou terceirizado em grandes empresas e Arranjos Produtivos Locais (APLs). O mel é processado nas "Casas de Mel” e os entrepostos responsáveis pelo processamento podem ser vinculados às associações, criadas por produtores ou órgãos públicos. Após o processamento, o mel é enviado para distribuidores que transportam o produto até supermercados, cooperativas etc., chegando, por fim, ao consumidor. Há também a venda direta, feita pelo produtor ou por associações e cooperativas (BUAINAIN; BATALHA, 2007).

A apicultura gera postos de trabalho, empregos e fluxo de renda para pequenos produtores da agricultura familiar, que no Brasil exploram até 150 colmeias, com mão-de-obra familiar e desenvolvendo paralelamente à apicultura outras atividades. Em tempos de colheita e migração, os pequenos produtores unem-se aos outros, dividindo custos. Transformar a participação individual em grupal e comunitária constitui uma "alavanca" para o crescimento da capacidade produtiva e comercial dos associados. Em associação, o grupo ganha força coletiva para dirigir os passos do desenvolvimento da comunidade (BUAINAIN; BATALHA, 2007). A apicultura é uma atividade em expansão que, além de intensificar a polinização da flora da região, atende a critérios do tripé da sustentabilidade - ecológico, social e econômico (DANTAS DE ALMEIDA; CARVALHO, 2009).

\subsubsection{Processo de Exportação e Dados sobre o Setor Apícola}

No Brasil o consumo de mel ainda é baixo, comparado ao de outros países, devido à falta de hábito da população que, geralmente, o utiliza para fins medicinais; pela relação direta entre 
poder aquisitivo e consumo; pela falta de informações a respeito das propriedades alimentares e medicinais, demonstrando a carência de marketing no setor. No mercado interno, o mel é vendido de forma fracionada (potes, bisnagas, sachês, garrafas), na rede atacadista e varejista. A comercialização a granel (baldes ou tambores) é realizada junto às indústrias (alimentícias, cosméticos, farmacêutica etc.) e aos Entrepostos dos Produtos das Abelhas (DANTAS DE ALMEIDA; CARVALHO, 2009). Já no mercado externo, o mel ainda tem atributo de commodity, pois, nas vendas, é embalado em tambores metálicos, com capacidade para 280 kg, e sua exportação é realizada a granel, em contêineres de 20 a 22 toneladas por remessa. No país de destino, o produto é fracionado e avaliado pela cor - o mel claro alcança preços superiores aos do mel escuro. A umidade é outro fator avaliado e determinante da qualidade (DANTAS DE ALMEIDA; CARVALHO, 2009).

Desde o ano 2009 até o final de 2013, o volume de mel brasileiro exportado em quilos sofreu variações, mas o preço médio pago por quilo de mel elevou-se gradativamente. No ano 2013 ano de realização do trabalho de campo desta pesquisa - foram exportadas 16 toneladas de mel, totalizando mais de 54 milhões de dólares. Enquanto no ano 2009 o mel era comercializado a $\mathrm{R} \$ 2,53 / \mathrm{kg}$, em 2013 chegou a $\mathrm{R} \$ 3,34 / \mathrm{kg}$ e em janeiro de 2015 alcançou o patamar de R \$3,98/kg. Em setembro de 2015, sofreu queda e foi comercializado a R\$3,49. As exportações corresponderam a 54 milhões de dólares em 2013 (ABEMEL, 2013; ABEMEL, 2015). Em 2014 as exportações chegaram a somar US\$ 98 milhões. Decerto, em função da atual conjuntura econômica brasileira, houve pequena desaceleração do montante exportado (e também, não se tem ainda o valor total do ano 2015). Assim, até setembro de 2015, o Brasil já tinha exportado US\$ 63 milhões em mel. Alemanha, Bélgica, Canadá e Estados Unidos, entre outros, destacam-se como maiores compradores do mel natural brasileiro (ABEMEL, 2015).

\subsection{ESTRATÉGIAS DE AÇÃO COLETIVA QUE VISAM À PROMOÇÃO DAS EXPORTAÇÕES DO SETOR}

A ABEMEL completou 10 anos em agosto de 2013, consolidando-se como entidade representativa do setor apícola brasileiro. No aniversário, divulgou em seu site institucional as conquistas de uma década de atuação, destacando que representa $90 \%$ das exportações setoriais e trabalha na otimização do desempenho das exportações do setor, facilitando o acesso aos mercados e negociações com toda a cadeia produtiva. Destacou ainda as parcerias, como a firmada com a Apex-Brasil, que promove a qualidade e competitividade dos produtos apícolas, por meio de ações focadas na promoção das exportações. 
Segundo a entrevistada gestora executiva da ABEMEL:

a própria constituição de uma associação setorial já é iniciativa de ação coletiva. As empresas perceberam que [...] precisavam estar organizadas por meio de entidade com representatividade coletiva reconhecida - assim nasceu a ABEMEL.

A entrevistada ressaltou ainda, conquistas da associação no período 2003 a 2013:

Por meio de articulações da ABEMEL linhas especiais de créditos (LEC) foram oferecidas a taxas de juros menores; foram firmados acordos e convênios de cooperação com o MDIC, a Apex-Brasil etc. O PSI, Projeto Setorial Integrado, junto a Apex-Brasil é um exemplo sucesso. As empresas demandaram esse convênio junto à Apex e então, por meio da associação, esta parceria foi efetivada.

O Planejamento Estratégico Setorial (PES) da ABEMEL contém três exemplos de ações coletivas: Feiras internacionais, Prospecção de Mercado e o Projeto Imagem. Outras ações que visam conquistas internas, tais como o Branding Setorial, o Projeto Design Export e o Projeto de Compras Coletivas de tambores para armazenamento e transporte de mel.

Entre as principais feiras internacionais do setor apícola estão a Apimondia e a Foodex Japan, que propiciam: exposição internacional de imagem; oportunidades comerciais; exposição das exigências internacionais de adequação de produto; lançamento de produtos; benchmarking com a concorrência etc. (PES, 2010). Pela primeira vez, em 2009, 17 associados à ABEMEL participaram de forma organizada da Feira Apimondia. Já a Prospecção de Mercado levanta informações sobre mercados-alvo, com foco na identificação de oportunidades para exportação de mel, canais de distribuição etc. (PES, 2010). Quanto ao Projeto Imagem, o foco é fortalecer a imagem setorial no mercado nacional e internacional. Jornalistas e formadores de opinião internacionais são convidados pelo Projeto de Exportação para virem ao Brasil $(I N)$ ou a eventos no Exterior (OUT) para que relatem sobre o setor, visando à publicação de informações no exterior (PES, 2010).

\subsubsection{Acesso, Participação e Benefícios das Ações Coletivas na ótica da gerência da} ABEMEL

Muitas das ações coletivas são viabilizadas pelo governo para atender necessidades de exportadores, de importadores, da associação e do próprio governo brasileiro. O processo decisório da ABEMEL pode ser descrito no depoimento da gestora entrevistada:

As decisões são tomadas por meio de reuniões participativas, em que são apresentadas demandas, sejam de ações focadas na exportação ou no mercado interno. A ABEMEL monitora questões técnicas, produtivas e comerciais e firma convênios para projetos coletivos. Por exemplo, preocupados com a adequação dos 
apiários brasileiros às exigências europeias, buscamos convênio junto ao MDIC para implantar o PAS-Mel (Programa Alimento Seguro para Mel) em "casas de mel”. Diversos entrepostos se organizaram para implantar o programa em casas de mel parceiras.

Assim, a ABEMEL decide onde investir, quais são as prioridades e que ações coletivas deve desenvolver:

\begin{abstract}
A associação, com o apoio da Apex-Brasil, fez em 2010 o planejamento estratégico setorial delineando quatro agendas de trabalho para os próximos cinco anos: ações de governança, políticas, foco na produção e foco na tecnologia, envolvendo todos os parceiros da cadeia apícola. As estratégias são propostas e validadas pelos associados em reuniões participativas. A entidade, quando propõe ações, também mobiliza e engaja as empresas para que participem de forma ativa (Gestora Entrevistada).
\end{abstract}

Não é necessário ser membro efetivo para participar das ações coletivas promovidas pela associação, pois: "a entidade permite que empresas associadas e não associadas se beneficiem e participem de das ações coletivas", segundo a gestora. Empresas não associadas pagam taxas para participar de eventos como feiras internacionais, rodadas de negócios etc. Há ações restritas aos associados como as visitas de importadores às empresas e publicações internacionais.

Para fazer parte da ABEMEL, a gestora explicou que: "as empresas precisam se inscrever $e$ demonstrar maturidade. Devem investir financeiramente sim, demonstrando comprometimento”. Porém, “dependendo do tipo de ação, a empresa tem ou não maturidade e competência para participar. Por exemplo, de uma ação na Europa, participarão apenas empresas habilitadas a exportar para Europa. Uma ação focada em mel, empresas que trabalham apenas com própolis não vão atuar”. Além de competência e maturidade, o tipo da ação coletiva também determina a participação, conforme depoimento: "Geralmente as ações coletivas têm grande procura, sobretudo aquelas ligadas ao Convênio com a ApexBrasil. Em 2011, em um universo de 28 empresas associadas, 21 empresas (18 associadas e três não associadas) participaram da APIMONDIA 2011".

$\mathrm{Na}$ visão da ABEMEL, segundo a gestora entrevistada, os principais benefícios da participação das empresas nas ações coletivas são: a) Benefício financeiro - órgãos de fomento apoiam uma coletividade visando o desenvolvimento setorial; b) Benefício de posicionamento - fortalecer e ser reconhecido; e c) Benefício de contribuírem com as ações organizadas, reduzindo o trabalho dentro da empresa. Portanto, se observa que as estratégias incluem negociações e articulações com stakeholders; parcerias e convênios; e inclusão no Projeto Setorial Integrado. 


\subsection{MOTIVAÇÕES DAS EMPRESAS PARA ASSOCIAR-SE À ABEMEL}

Em 2002, quando a China e a Argentina, principais fornecedores mundiais de produtos derivados de mel, tiveram suas exportações suspensas por compradores europeus sob alegação de contaminação por Clorafenicol (SEBRAE, 2006b), a demanda por importação de mel de qualidade acirrou-se, propiciando a inserção de produtores e exportadores brasileiros, que não eram exportadores tradicionais, e que redirecionaram a venda de parte do produto antes vendida internamente - para o mercado externo (BUAINAIN; BATALHA, 2007). Assim surgiu a ABEMEL no ano 2003, estruturando e coordenando ações, juntamente com o governo Brasileiro, a fim de se destacarem nas pautas de exportação. O entrevistado E2, um dos idealizadores da associação, afirmou que a ABEMEL surgiu "pela necessidade que enfrentamos no embargo ao mel na Europa. O governo brasileiro somente atendia entidade e não empresa privada". Havia a "necessidade de negociar com governo e conseguir recursos em órgãos públicos para viabilizar negócios e projetos". Um dos fatores para a formação de redes é a união motivada pela oportunidade de obter maior acesso a recursos, pois a rede facilita o acesso a novos mercados, tecnologias e suprimentos (HUMAN; PROVAN, 1997).

$\mathrm{O}$ entrevistado $\mathrm{E} 1$ afirmou que se associou, pois precisava "unir forças e resolver os problemas da classe". A cooperação é uma estratégia de resposta às complexidades do ambiente (DOTTO; WITMANN, 2003) em que os associados são estimulados e guiados por um objetivo comum (COSTA, 2005). O entrevistado E3 afirmou que: "na época não era ABEMEL. Aconteceu durante o Congresso Brasileiro de Apicultura em 2002, em Florianópolis-SC", e que precisavam se associar para: “ter legitimidade representativa perante os órgãos oficiais e os clientes. Juntos somos mais fortes e fica mais fácil brigar pelos nossos direitos. Organizar e profissionalizar o setor”. A união visando o alcance de credibilidade e legitimidade externa também é uma das motivações para a formação das redes (HUMAN; PROVAN, 1997).

$\mathrm{O}$ entrevistado E4 se associou visando: "fortalecer uma entidade de classe nacional; compartilhar estratégias e ações comerciais como participação em feiras e eventos internacionais; lutar pelos interesses do setor junto aos órgãos governamentais...”. Estes motivos significam trocas interorganizacionais, visando o compartilhamento das práticas entre envolvidos, e a solução de problemas comuns, com o aumento do fluxo de informações e de negociações (HUMAN; PROVAN, 1997). Assim, conclui-se que as motivações para unir esforços visam à consecução de recursos para acesso a novos mercados, atendimento de demandas externas, conquista de legitimidade e fortalecimento da representatividade do setor. Estes pontos serão um pouco mais discutidos a seguir. 


\subsection{GANHOS DAS AÇÕES COLETIVAS NA ÓTICA DOS ASSOCIADOS DA} ABEMEL

Considerando os depoimentos de quatro entrevistados e classificando-os por categorias de ganhos percebidos - (1) ganhos de escala e poder de mercado; 2) acesso a soluções; 3) aprendizagem e inovação; 4) redução de custos e de riscos; e 5) relações sociais) (VESHCOORE, 2006; BALESTRIN E VERSCHOORE, 2008) -, constatou-se que das cinco categorias de ganhos, três não foram explicitadas nos depoimentos: acesso a soluções; redução de custos e riscos; e relações sociais. Os quatro entrevistados apenas relacionaram os ganhos advindos das ações coletivas aos ganhos de escala e poder de mercado, e ao aprendizado e inovação, conforme depoimentos. Os entrevistados E1, E2 e E4 apontaram como ganhos percebidos: A) Ganhos de Escala e de Poder de mercado: E1 - "abertura de leque de mercado e clientes."; E2- "Divulgação da empresa, possibilidade de participar de feiras e eventos internacionais, imagem, ampliação dos mercados". B) Aprendizagem e Inovação: E4- "Abertura e ampliação de mercados, reforço da imagem dos produtos apícolas no mundo através de ações conjuntas"; E2- "conhecer melhor os mercados para tomada de decisões acertadas".

A ABEMEL funciona, portanto, como canal para o processo de aprendizagem e inovação. Quando há maior comunicação e abertura das empresas entre si, estas recebem mais informações e difundem na rede o conhecimento. Assim, as inovações e os avanços tecnológicos podem ser alcançados coletivamente (BALESTRIN; VARGAS, 2004).

Além dos depoimentos, o questionário composto pelas cinco categorias de ganhos percebidos, foi respondido por 10 participantes, codificados de P1 a P10. A amostra é pequena para trabalhar com estatística inferencial e até mesmo descritiva, porém há considerável representatividade, tendo em vista que do universo de 23 proprietários/gestores que participam da ABEMEL, $10(43,5 \%)$ responderam a pesquisa. Portanto, ainda que ilustrativamente, optou-se pela extração das médias mais significativas, visando à análise dos principais ganhos percebidos na ótica dos associados.

Observou-se que as médias variaram entre a máxima de 3,7, com desvio padrão de 1,5 e a mínima de 1,7, com desvio padrão de 1,3. Considerando a gradação de 1 (discordo totalmente) a 5 (concordo totalmente), obtém-se a seguinte distribuição: 1) Redução de Custos e Riscos, cuja assertiva: "Conseguimos fazer mais ações com menos recursos" obteve média 3,7 (dp=1,5); 2) Provisão de Soluções, cuja assertiva: "São disponibilizados suporte e recursos efetivos para ações coletivas" obteve média 3,4 $(\mathrm{dp}=1,4)$; Ganhos de Escala e Poder de mercado, cuja assertiva: "Há muitos parceiros importantes engajados na rede" 
obteve média 3,1 (dp=1,2); novamente a Provisão de Soluções, cuja assertiva: "A estrutura é eficiente e focada na abertura de novos mercados" obteve média 3,1 $(\mathrm{dp}=1,1)$; e outra vez os Ganhos de Escala e Poder de mercado, cuja assertiva: "Produtos do setor apícola alcançaram maior reconhecimento no mercado" obteve média 3,0 $(\mathrm{dp}=1,5)$.

Ressalta-se a importância dos Ganhos de Escala e de Poder de mercado, bem como das Provisões de Solução proporcionadas pela associação, citados nas entrevistas e com médias mais expressivas no questionário. A literatura propõe que a formação de redes reduz a incidência de custos e é relevante na superação de dificuldades e maximização do uso de recursos (JARILLO, 1993; VERSCHOORE, 2006; BALESTRIN; VERSCHOORE, 2008). O Ganho de Aprendizagem e Inovação foi citado apenas nas entrevistas e as Relações Sociais não tiveram destaque em nenhum dos instrumentos.

\subsection{MOTIVAÇÕES DOS ASSOCIADOS DA ABEMEL PARA EXPORTAR}

As motivações para exportar devem estar calcadas no propósito de desenvolvimento da empresa, com vistas à exploração de competitividade; à obtenção de ganhos em outros mercados: à maximização do uso de instalações; à melhoria da produtividade e redução de custos; à superação de dificuldades no mercado interno; além da diversificação de mercados, que a impulsionam rumo ao desenvolvimento tecnológico e à melhoria da qualidade dos produtos (MINERVINI, 2012).

Para o associado E3, entre as motivações para exportar estavam: "primeiro o fator financeiro, segundo o mercado estava aberto, por causa da contaminação do mel chinês, ou seja, pela demanda de mercado". O entrevistado E4 citou a "ampliação de mercado"; tendo em vista a "capacidade de produção da empresa para atender novos mercados [...] havia grande interesse de países asiáticos pelo produto". O entrevistado E1 afirmou que sua motivação envolve o "volume e menor risco de calote", enquanto o entrevistado E2 revelou que "o mercado brasileiro não absorve toda produção e a empresa já nasceu exportando própolis para o Japão”.

Nota-se que as motivações para associar-se demonstradas na seção 3.3, relacionam-se com as motivações para exportar, pois quando surge a oportunidade de exportar, as empresas percebem que podem obter apoio através da atuação conjunta. Classificando as motivações em proativas e reativas (PALACIOS; SOUSA. 2004), verificou-se a predominância da motivação reativa, que se origina nas influências (ou pressões) externas. 
3.6 BARREIRAS À EXPORTAÇÃO DE PRODUTOS APÍCOLAS, NA ÓTICA DE EXPORTADORES ASSOCIADOS À ABEMEL

Classificando as barreiras à exportação em quatro blocos, segundo Minervini, (2012), os entrevistados citaram as seguintes barreiras, conforme se verifica no Quadro 1, a seguir:

Quadro 1: Barreiras às exportações apontadas pelos entrevistados associados à ABEMEL

\begin{tabular}{|c|c|c|c|c|}
\hline $\begin{array}{c}\text { Tipos de } \\
\text { barreiras } \\
(\text { MINERVINI, } \\
\text { 2012) }\end{array}$ & E1 & $E 2$ & E3 & $E 4$ \\
\hline $\begin{array}{l}\text { Barreiras por } \\
\text { parte do } \\
\text { exportador. } \\
\end{array}$ & & & $\begin{array}{c}\text { "...desde } \\
\text { inexperiência,..." }\end{array}$ & $\begin{array}{c}\text { "Disseminar a } \\
\text { cultura } \\
\text { exportadora..." }\end{array}$ \\
\hline $\begin{array}{l}\text { Barreiras por } \\
\text { parte do país } \\
\text { exportador. }\end{array}$ & & $\begin{array}{c}\text { "Legislação } \\
\text { brasileira [...]" } \\
\text { "Custo de abertura } \\
\text { de um mercado é } \\
\text { altíssimo..." }\end{array}$ & & $\begin{array}{l}\text { “...falta de recurso } \\
\text { financeiro para } \\
\text { promover ações } \\
\text { internacionais." }\end{array}$ \\
\hline $\begin{array}{l}\text { Barreiras por } \\
\text { parte do } \\
\text { importador }\end{array}$ & & & $\begin{array}{c}\text { “..falta de } \\
\text { credibilidade por } \\
\text { parte dos } \\
\text { importadores..." }\end{array}$ & \\
\hline $\begin{array}{l}\text { Barreiras por } \\
\text { parte do país } \\
\text { importador }\end{array}$ & $\begin{array}{l}\text { "Embargo do mel } \\
\text { em 2003." }\end{array}$ & $\begin{array}{l}\text { "Embargo ao mel no } \\
\text { mercado EUROPEU } \\
\text { em 2006..." }\end{array}$ & $\begin{array}{l}\text { "...o embargo } \\
\text { europeu ao mel } \\
\text { brasileiro." }\end{array}$ & $\begin{array}{c}\text { “...adaptar-se as } \\
\text { diferenças culturais } \\
\text { dos países..." } \\
\text { "...conhecer as } \\
\text { necessidades de cada } \\
\text { mercado" }\end{array}$ \\
\hline
\end{tabular}

Fonte: Dados da pesquisa, 2013.

As dificuldades originadas no Brasil são os custos elevados, dificuldades para obter financiamentos e as legislações excessivas. O entrevistado E4 citou que "o mercado internacional demanda muitos produtos e o MAPA dificulta o desenvolvimento das empresas brasileiras. Por ex.: o governo brasileiro não permite a comercialização de própolis em capsulas então, tivemos que fazer parceria com uma empresa no Japão para terceirizar a fabricação". Assim, as principais barreiras percebidas são originadas no país exportador (MINERVINI, 2012).

\subsection{ESTRATÉGIAS ADOTADAS PARA SUPERAÇÃO DE BARREIRAS À EXPORTAÇÃO DE PRODUTOS APÍCOLAS}

Como estratégias de superação de barreiras à exportação, três, entre quatro entrevistados, citaram a participação nas ações coletivas. O entrevistado E1 cita a "criação da ABEMEL, e a união entre os exportadores para resolver os problemas.”. O entrevistado E2 destaca que “...ações coletivas são primordiais para superar as barreiras internas e para conseguir exportar...”. O entrevistado E4 investiu em "participação em ações conjuntas no mercado 
internacional e contratação de mão de obra especializada". Já o entrevistado E3 é mais incisivo em relação às estratégias para superar as barreiras, e afirma que "[...] o Brasil produz $5 \%$ do mel colhido no mundo. A única estratégia é sermos indispensáveis, ou seja, certificar todo nosso mel como orgânico". Apesar de nem todos terem citado a associação, ou ações coletivas, infere-se que, por depender do esforço de todos para realizá-la, a rede se torna um dos meios estruturados para incentivar e promover a "estratégia de ser indispensável" por meio do esforço de certificação do mel orgânico.

\subsection{DESAFIOS FUTUROS DAS AÇÕES COLETIVAS NA ÓTICA DE ASSOCIADOS À} ABEMEL

Considerando as motivações para se associar e para exportar os ganhos que podem ser conquistados por meio da associação para ação coletiva, as barreiras que se têm de enfrentar e as estratégias que podem ser adotadas, buscou-se compreender, por último, quais estratégias os associados consideram relevantes para o processo de exportação e que ainda não foram alcançadas, quais seriam os benefícios esperados, e se em suas óticas a associação poderia ajudar. O Quadro 2, a seguir, resume as percepções de associados entrevistados.

Quadro 2: Principais desafios futuros das ações coletivas na ótica dos associados

\begin{tabular}{|c|c|c|c|}
\hline & $\begin{array}{c}\text { OBJETIVOS } \\
\text { ESTRATÉGICOS } \\
\text { RELEVANTES, AINDA NÃO } \\
\text { ALCANÇADOS }\end{array}$ & BENEFICIOS ESPERADOS & $\begin{array}{c}\text { ASSOCIAÇÃO PODE } \\
\text { AJUDAR? }\end{array}$ \\
\hline E1 & $\begin{array}{l}\text { "Aumento da produção de mel } \\
\text { brasileiro...". }\end{array}$ & & $\begin{array}{lr} & \text { "Com a ABEMEL, SEBRAE } \\
\text { e APEX } & \text { sendo nossos } \\
\text { parceiros, com } & \text { certeza } \\
\text { alcançaremos este objetivo". }\end{array}$ \\
\hline $\mathbf{E 2}$ & $\begin{array}{l}\text { "Sair da venda de mel a granel } \\
\text { e iniciar com valor agregado } \\
\text { com a marca Bee Brazil. } \\
\text { Divulgação do produto nos } \\
\text { mercados alvos - ações de } \\
\text { propaganda". }\end{array}$ & $\begin{array}{l}\text { "Ter o produto final na } \\
\text { prateleira, para o consumidor } \\
\text { final". }\end{array}$ & $\begin{array}{l}\text { "A associação pode ajudar } \\
\text { captando projetos para este } \\
\text { fim." }\end{array}$ \\
\hline $\mathbf{E 3}$ & $\begin{array}{l}\text { "[...] abrir a cabeça do MAPA- } \\
\text { Ministério da Agricultura, } \\
\text { Pecuária e Abastecimento e } \\
\text { acabar com essa palhaçada de } \\
\text { ER (Relacionamento do } \\
\text { Estabelecimento) em todo o } \\
\text { Brasil. Isso é muito difícil } \\
\text { conseguir; só com o apoio de } \\
\text { todas as entidades do setor." }\end{array}$ & $\begin{array}{l}\text { "Sobrevivência das empresas e } \\
\text { elevar o nome e a qualidade do } \\
\text { mel brasileiro." }\end{array}$ & --- \\
\hline E4 & $\begin{array}{l}\text { "Conquistar maior apoio dos } \\
\text { órgãos governamentais } \\
\text { principalmente do Ministério da } \\
\text { Agricultura para aprovação e } \\
\text { liberação de novos produtos e } \\
\text { agilidade na aprovação de }\end{array}$ & $\begin{array}{l}\text { "O mercado internacional } \\
\text { demanda de muitos produtos e } \\
\text { o MAPA dificulta o } \\
\text { desenvolvimento das empresas } \\
\text { brasileiras. Ex: O governo } \\
\text { brasileiro não permite a }\end{array}$ & $\begin{array}{l}\text { "Acreditamos que a associação } \\
\text { poderá contribuir muito como } \\
\text { interlocutora das empresas } \\
\text { junto ao Ministério da } \\
\text { Agricultura, Pecuária e } \\
\text { Abastecimento, que ao invés de }\end{array}$ \\
\hline
\end{tabular}




\begin{tabular}{|l|l|l|l|}
\hline & rótulos e embalagens." & $\begin{array}{l}\text { comercialização de própolis em } \\
\text { capsulas então, tivemos que } \\
\text { fazer parceria com uma está prejudicando as a }\end{array}$ & ações das empresas apícolas.” \\
empresa no Japão para & \\
terceirizar a fabricação". & \\
\hline
\end{tabular}

Fonte: Dados da pesquisa, 2013.

Fica evidente que as barreiras impostas pelo país exportador (MINERVINI, 2012) se manifestam, nas falas dos sujeitos da pesquisa, de maneira contundente no setor apícola no Brasil, por causa de burocracia/legislação. Com relação à criação de uma marca, a literatura (BUAINAIN; BATALHA, 2007) reforça que o produto muda de imagem e deixa de ser comercializado como mais uma commodity do agronegócio brasileiro, passando a ser reconhecido pela procedência, valor e qualidade.

\section{CONCLUSÕES}

O estudo permite concluir que os ganhos da atuação em coletividade, ainda que sem a percepção clara da importância das relações sociais por parte dos associados, são vistos como fomentadores de estratégias de atuação futura, com vistas à superação de dificuldades de acesso a financiamentos e a mercados e de problemas com a legislação e burocracia. Há forte percepção de barreira imposta pelo país exportador, em que pesem destacarem as ações promocionais investidas pela ABEMEL, em convênios com Apex, SEBRAE entre outros atores.

As ações coletivas podem facilitar o processo de exportação de produtos apícolas do Brasil. Entretanto, a ABEMEL é, na ótica dos associados, apenas um dos atores relevantes para estruturação do setor. Os desafios percebidos pelos sujeitos são maiores e demandam esforços governamentais e empresariais mais contundentes.

A pesquisa tem limitações tais como: o acesso a poucos sujeitos. Optando pelo enfoque da ótica dos associados e da gerência executiva da associação, tem-se a visão apenas de duas classes de sujeitos envolvidos com a ABEMEL. Sabe-se que a multivocalidade é algo valioso em trabalhos de abordagem qualitativa. Em estudos futuros mais vozes poderão incrementar o processo de triangulação.

A contribuição do estudo pode estar relacionada com a obtenção da visão dos associados para o Setor Apícola Brasileiro, que é composto por vasta diversidade de produtos, produtores e de necessidades, para a ABEMEL, para o governo brasileiro - especialmente a Apex e o MAPA e para a literatura. 
Como sugestão para pesquisas futuras, propõe-se o levantamento e a classificação da maturidade exportadora das organizações associadas, para então comparar diferenças de percepções a partir de diferentes níveis de maturidade no setor apícola brasileiro. 


\section{REFERÊNCIAS}

ABEMEL. Site Institucional. Disponível em: <www.abemel.com.br> Acesso em 12 nov., 2013.

ABEMEL. Site Institucional. Setor Apícola Brasileiro em Números. Disponível em: < http://brazilletsbee.com.br/inteligencia_comercial_abemel_setembro_2015.pdf/> Acesso em: 22 nov., 2015.

BALESTRIN, Alsones. A dinâmica da complementaridade de conhecimentos no contexto das redes interorganizacionais. Porto Alegre: UFRGS, 2005. 214 f. Tese (Doutorado em Administração), Universidade Federal do Rio Grande do Sul, Porto Alegre, 2005.

BALESTRIN, Alsones.; VARGAS, Lília M. A Dimensão Estratégica das Redes Horizontais de PMEs: Teorizações e Evidências. RAC, Edição Especial, p. 203-227, 2004.

BALESTRIN, Alsones.; VERSCHOORE, Jorge R. Fatores relevantes para o estabelecimento de Redes de Cooperaçăo entre empresas do Rio Grande do Sul. RAC, Curitiba, v. 12, n. 4, p. 1043-1069, out./dez, 2008.

BARDIN, Laurence. Análise de conteúdo. Lisboa: Edições 70, 1977.

BRASIL. Ministério Desenvolvimento Indústria e Comércio Exterior (MDIC). Termo de referência: internacionalização de Empresas brasileiras. Brasília, 2009. Disponível em: < http://www.mdic.gov.br/arquivos/dwnl_1260377495.pdf > Acesso em 22 out., 2013.

BRASIL. Ministério da Agricultura, Pecuária e Abastecimento (MAPA). Secretaria Executiva. Agenda Estratégica Mel e Produtos das Abelhas 2010 - 2015. Brasília - DF, 2011.

BRASIL. Ministério das Relações Exteriores (MRE). Divisão de Programas de Promoção Comercial. Exportação Passo a Passo / Ministério das Relações Exteriores. - Brasília: MRE, 268 p., 2011.

BUAINAIN, Antônio M.; BATALHA, Mário O. Cadeia produtiva de flores e mel. Brasília: IICA: Mapa/SPA, Agronegócio, v. 9, 140 f., 2007.

BUCKLEY, Peter.; CROSS, Adam.; TAN, Hui.; XIN, Liu. Historic and emergent trends in Chinese outward direct investment. Management International Review, 48(6), 715-748, 2008.

COSTA, Helena A. Análise das relações de rede e do perfil da competitividade turística: Estudo comparativo entre São Francisco do Sul e Laguna - Santa Catarina. 2005. 188 f. Tese (Mestrado em Turismo e Hotelaria) -. Universidade do Vale do Itajaí - UNIVALI, Santa Catarina, 2005. Disponível em: <http://siaibib01.univali.br/pdf/Helena\%20Costa.pdf> Acesso em: 22 out., 2013.

DANTAS DE ALMEIDA, Marco A.; CARVALHO, Corália M. S., Apicultura: uma oportunidade de negócio sustentável. Salvador: Sebrae Bahia, 2009. 
DOTTO, Dalva M. R.; WITTMANN, Milton L. As Redes de Pequenas e Médias Empresas do Vale do Rio Pardo e Taquari do Rio Grande do Sul, Brasil: uma análise de estratégias de cooperação empresarial e desenvolvimento regional. VII Congreso Internacional del CLAD sobre la Reforma del Estado y de la Administración Pública. (Anais...) Panamá, p.28-31, out., 2003.

GULATI, Ranjay; NOHRIA, Nitin; ZAHEER, Akbar. Redes estratégicas. Strategic Management Journal, 21, p.203-215, 2000.

HALL, Colin M.. Planejamento turístico: políticas, processos e relacionamentos. São Paulo: Contexto 2001

HILAL, Adriana; HEMAIS, Carlos A. O processo de internacionalização na ótica da escola nórdica: evidências empíricas em empresas brasileiras. Revista de Administração Contemporânea, 7(1), 109-124, 2003.

HUMAN, Sherrie E.; PROVAN, Keith G. An emergent theory of structure and outcomes in Small firm strategic manufacturing network. Academy of Management Journal, v. 40, n. 2, p. 368-403, 1997.

JARILLO, J. Carlos. On Strategic Networks. Strategic Management Journal, vol.9, p. 31$41,1988$.

JARILLO, J. Carlos. Strategic networks: creating the borderless organization. Oxford: Butterworth-Heinemann, 1993.

LADEIRA, Wagner J.; ARAUJO, Clecio F. Aproximações entre "global sourcing" e integração produtiva: uma análise da internacionalização das atividades produtivas no contexto brasileiro. Revista Ibero-Americana de Estratégia. RIAE, São Paulo, v. 10, n. 2, p. 04-33, mai./ago, 2011.

LENGLER, Letícia; LAGO, Adriano; CORONEL, Daniel A. A organização associativa no setor apícola: contribuições e potencialidades. Organizações Rurais e Agroindustriais, Lavras, v. 9, n. 2, p. 151-163, 2007.

LENGLER, Silvio. Organizar o setor apícola é o caminho. Revista Brasileira de Agropecuária, [S.1.], ano 3, n. 15, 2001.

LOPEZ, José M. C.; GAMA, Marilza. Comércio exterior competitivo. 3 ed., São Paulo: Aduaneira, 2007.

MAIS, Ilisângela; CARVALHO, Luciano C.; AMAL, Mohamed; HOFFMANN, Micheline G. Importância das redes nos processos de inovação e internacionalização de empresas de base tecnológica RAI - Revista de Administração e Inovação, São Paulo, v. 7, n. 1, p. 36-52, jan./abr, 2010.

MINERVINI, N. O exportador. Editora: Pearson Education, 6. Ed, 2012. 
PAULA NETO, Francisco L.; ALMEIDA NETO, Raimundo M. Principais mercados apícolas mundiais e a apicultura brasileira. Sociedade Brasileira de Economia e Sociologia Rural, Ribeirão Preto, Jul., 2005.

PES: Planejamento Estratégico Setorial, ABEMEL, São Paulo, 2010.

RANGEL, Rogério. Mel brasileiro conquista o mercado externo. Revista Inovação em Pauta, 10, 56-61, 2010.

SEBRAE. Revista. Desafios da apicultura brasileira. Sebrae Agronegócios, n. 3, maio 2006b.

PALACIOS, Tomás M. B.; SOUSA, José M. M. De. Estratégias de Marketing Internacional. São Paulo: Atlas, 2004.

STAL, Eva. Internacionalização de empresas brasileiras e o papel da inovação na construção de vantagens competitivas. Revista de Administração e Inovação, São Paulo, v. 7, n. 3, p.120 - 149, jul./set, 2010.

VERSCHOORE, Jorge R. S. Redes de cooperação interorganizacionais: a identificação de atributos e benefícios para um modelo de gestão. Porto Alegre: UFRGS, 2006. 253 f. Tese (Doutorado em Administração), Universidade Federal do Rio Grande do Sul, Porto Alegre, RS, $2006 . \quad$ Disponível em:< http://www.lume.ufrgs.br/bitstream/handle/10183/6567/000531847.pdf?sequence=1> Acesso em: 23 out, 2013.

United Nations Conference on Trade and Development (UNCTAD). TRADE AND DEVELOPMENT BOARD. Commission on Enterprise, Business Facilitation and Development Expert Meeting on Promoting the Export Competitiveness of SMEs. Item 3 of the provisional agenda. Geneva, p.8-10, December, 2004. 